\title{
Relationship between Common Errors of Communication among Psychiatric Nursing Students and Anxiety Levels of their Assigned Patients
}

\author{
Walaa Farahat Abd Alaziz Elsobky ${ }^{1}$, Maaly Ibrahim El-Malky ${ }^{2}$ and Faten Mohamed Ahmed ${ }^{3}$
}

(1) Head Nurse in Kafr-Elsheikh General Hospital, (2) Professor of Psychiatric and Mental Health Nursing , Faculty of Nursing, El Menoufia University and (3) Assist. Prof. of Psychiatric and Mental Health Nursing, Faculty of Nursing, Benha University.

\section{Abstract:}

Background: Communication errors reflect excess anxiety levels of both patients and students. Anxiety symptoms of psychiatric patients are commonly intertwined with communication errors of nursing students. The aim of this study was to determine the relationship between common errors of communication among psychiatric nursing students and anxiety levels of their assigned patients. Research design: Descriptive correlational design was utilized to achieve the aim of this study. Setting: The study has been conducted at the Psychiatric Mental Health Hospital in Benha City which is affiliated to the General Secretariat. Sample: A convenient sample of all the academic $4^{\text {th }}$ year students who were undergoing psychiatric nursing experience at Faculty of Nursing; Benha University, 180 students and their assigned patients 180 patient were recruited. Tools of data collection: Two tools were used. I: Structured interviewing sheet consisting of two parts; to assess personal characteristics and common errors of communication among psychiatric nursing students during their clinical experience. II: Anxiety scale to assess level of anxiety of psychiatric patients. Results: $84.4 \%$ of students have communication errors ranged from mild to high and $85 \%$ of the studied patients have anxiety ranged from extreme to moderate level. There is statistically significant positive correlation between total mean score of communication errors of the students and total mean score of patients anxiety at p-value $=(0.04)$. Conclusion: The comorbid anxiety symptoms are highly prevalent among psychiatric patients due to communication errors of nursing students. When communication errors increases levels of anxiety increases. Recommendations: Educational programs of communication skills should be conducted for all nursing students to minimize their communication errors and minimize their assigned patient's anxiety.

Key words: Communication errors, Levels of Anxiety, Nursing Students, Psychiatric Patients, Clinical Practice.

\section{Introduction}

Communication is one of the essential factors to maintain a good quality of life because it allows humans to interact and provide comfort. Communication includes verbal and nonverbal. During verbal communication, there are many factors that affect the choice of words, for example, age, race, socioeconomic status, education background, gender, place, and the situation. Nonverbal communication includes body language, facial expression, and active listening. The ability to classify information in ways that can be understood by self and others would be severely impaired if spoken languages were not used (Dawood et al., 2018). 


\section{Relationship between Common Errors of Communication among Psychiatric Nursing Students and Anxiety Levels of their Assigned Patients}

The concept of "Communication" refers to the process in which the nurse consciously influences patients or helps the patients to a better understanding through verbal and nonverbal communication. Communication involves the use of specific strategies that encourage the patient to express feelings and ideas and that convey acceptance and respect. However, the concept has been defined further more by different scholars analyzing the terms separately, in terms of words structure and meaning. Communication defined as the act or reciprocal process of imparting or interchanging thoughts, attitudes, emotions, opinions, or information by speech, writing, or signs (Houwen et al., 2019).

According Cvetic, (2018), suggests that, in the nurse-patient relationship, communication involves more than the transmission of information. It also involves transmitting feelings, recognizing these feelings and letting the patients know that their feelings have been recognized (Raya, 2018), support this view and indicate that communication is a fundamental part of nursing and that the development of a positive nurse-patient relationship is essential for the delivery of quality nursing care. When there is a difference in status or power between student and patient, the relationship is characterized to be in equally it exists when there is a difference in status between the participants, for example, in all cultures social status, age or developmental differences, gender differences and educational differences can be influential in the communication process (Szpak \& Kameg, 2017).

Communication is also affected by attitude, which determines how one person generally responds to another person and includes one's biases, past experiences, and levels of openness and acceptance. Also, people from one socioeconomic class, ethnic background, or family background may have a difficult in communicating with individuals from a different background or class, possibly because of language, value, and knowledge barriers (Hart, 2018).

Communication errors shatters the nurse-patient curative relationship and acts as a barrier in look of patient's feelings which may take to blemish nursing attention. Nurses' communication errors leaves a negative image in a patients' head sing nurse and the establishment, impacting greatly on his anxiety level and intervention. Patient would non show but construct on feelings deep inside, which can take to anxiety, stress and/or depression. Through positive respect, confidence and encouragement, the nurse could hold helped the patient. Alternatively, the nurse demoted him and lowered his self-pride (Marzieh et al., 2020).

Some patients do not trust anyone, so they are suspicious. Some patients would question everything the student does. Other patients regress and become dependent on the nursing students. Other become isolated and reject everything the student tries to do. Be patient and open minded with all patients. Reassure them and make sure that the patient is not a danger to self or others. Let all patients know you care, but do not allow them to participate in dangerous or threatening behaviors. Encourage independence in all patients (Hall, 2017). 


\section{Walaa Farahat Elsobky, Maaly Ibrahim El-Malky and Faten Mohamed Ahmed}

The nurses' goal must be implement measures to facilitate communication, avoidance of communication errors and lower the patient's anxiety level before proceeding with anything else. So, nursing students must be clarify ideas before attempting to communication and explain the purpose of the communication, maintain a patient calm and allow suitable time for communication, provide good climate and safe, quite environment so that patient can concentrate on communication efforts, nursing students must provide trust and confidence, change the tone of voice, maintain eye contact and active listening, avoid using unrelated questions and, use simple clear language understood by patient, and all of this may lead to a reduction in patient's anxiety levels (Pesut et al., 2019).

\section{Significance of the study}

Effective communication is a fundamental element in all nursing and forms an integral part of quality patient care. In addition, communication is important for patient safety. The Joint Commission on Accreditation of Healthcare Organizations (JCAHO) claims that $65 \%$ of adverse events or incorrect treatment is associated with communication failure (Fay-Hillier et al., 2012). In its description of core competencies in the health profession, the US Institute of Medicine recommends increased focus on improving professional communication, cooperation and a patient-centered approach in order to strengthen patient safety and psychological wellbeing (Liaw et al., 2014).

The prevalence and severity of anxiety level among psychiatric patients is increasing. Many studies show that anxiety level of psychiatric patients is elevated within a reason of non-therapeutic communication (communication errors) of nursing students. Elevated level of patient anxiety may interfere with building interpersonal relationship between nurse and patient by putting barriers in the way of open discussion, trusting and respectful dialogue. patient anxiety level is characterized by a feeling of dread or uncomfortable anticipation with physical, behavioral and cognitive features, this has a negative effect on nurses' clinical performance that may be effect on patient health state (Poyato et al., 2016). When a patient's anxiety loses its link with precipitating circumstances or becomes excessive or maladaptive that patient is said to be experiencing anxiety disorder (Wedgeworth, 2016).

So, this study will be conducted to determine the relationship between common errors of communication among psychiatric nursing students and anxiety levels of their assigned patients.

\section{Aim of the study}

The aim of this study was to assess the relationship between common errors of communication among psychiatric nursing students and anxiety levels of their assigned patients.

\section{Research Questions:}

1- What is the level of common errors of communication among psychiatric nursing students during their clinical experience?

2- What are the levels of anxiety among psychiatric patients?

3- What is the relationship between common errors of communication among psychiatric nursing students and anxiety level of their assigned patients? 
Subjects and methods

Research design:

A descriptive correlational design was utilized to achieve the aim of the study.

\section{Research setting:}

The study was conducted at the Psychiatric and Mental Health Hospital in Benha City, which is affiliated to General Secretariat of Mental Health, it has (7) departments (4 male, 1 female, 1 addiction department and 1 outpatient clinic), with a capacity of (295) bed. The hospital provides care for patients diagnosed with acute and chronic mental illness who need institutional care. The total number of staff nurses was (225) nurse, the hospital provides care at three shifts divided in to the first shift starting from 8 a.m. and ending to 2 p.m. second shift starting from 2 p.m. and ending 8 p.m. The third and last shift starting 8 p.m. and ending 8 a.m. Total number of patients in male and female departments (180) patient, (122 male and 58 female) were included in the study.

\section{Sample:}

A convenient sample technique. The study subject was including all the academic $4^{\text {th }}$ year students who were undergoing psychiatric nursing experience at Faculty of Nursing; Benha University during the academic year (2018-2019) at the second semester. A number of the students were 180 student and their assigned patients 180 patient who fulfill the inclusion criteria.

\section{Inclusion criteria:}

- $4^{\text {th }}$ year basic B.Sc. Nursing students and their assigned patients.

- Both sexes.

- Accept to participate in the study.

\section{Tools of data collection: -}

In order to achieve the aim of the study the following tools were being used:

Tool (I): Structured interviewing sheet which was divided in to two parts;

Part (1) Socio-demographic characteristics of the students as age, sex, marital status and residence

Part (2) Observational check list was developed by the researcher and it was used to assess common errors of communication among psychiatric nursing students during their clinical experience.

Nursing students' communication errors were involved 25 items

Each item was scored on a 3-point Likert-scale of 1-3 (based on these replies: "yes $=3$," "sometimes $=2, "$ "no $=1$ "). Overall assessment was done by total score. The total scores range from 25-75.

Scoring system of communication errors were categorized as follows:

- (less than 37) No communication errors.

- (37-54) Student has a slight (mild) communication errors.

- (55-72) Student has a moderate communication errors.

- (more than 72) Student has a great (high) communication errors.

Tool (II): Was consisted of three parts;

Part (1) Socio-demographic characteristics of the patients as (age, sex, marital status, level of education, occupation and residence 


\section{Walaa Farahat Elsobky, Maaly Ibrahim El-Malky and Faten Mohamed Ahmed}

Part (2) Clinical data: which include (onset of disease, number of previous admissions and the last period of staying in the hospital

Part (3) Zung Anxiety Status Inventory (ASI) it was developed by (Bayoumi et al., 2012) to measured state and trait of anxiety. It was a self-report assessment device which includes 20-item. Answering the statements, a person would indicate how much each statement applied to patient. Each question was scored on a Likert-type scale of 1-4 (based on these replies: "a little of the time," "some of the time," "good part of the time," "most of the time"). Overall assessment was done by total score. The total scores range from 20-80.

\section{Scoring system of anxiety scale was categorized as follows:}

- (20-44) Normal Range.

- (45-59) Mild to Moderate Anxiety Levels.

- (60-74) Marked to Severe Anxiety Levels.

- (75-80) Extreme Anxiety Levels.

\section{Content validity of the tools:}

Tools were provided to the jury of 5 experts in the psychiatric nursing (5 assistant professors). Tools were checked for the relevancy, clarity, comprehensiveness, and applicability of the questions. The tool was proved to be valid. Modifications were done in the two scales used in the research study.

\section{Reliability of the tool:}

Internal consistency of the tools were checked by test retest reliability. Tools were strongly reliable at $(0.84)$ for communication error tool and at (0.92) for anxiety scale.

\section{Ethical consideration:}

All subjects who agreed to participate in the study were assured about the confidentiality and anonymity of the study. They were informed that they could withdrawal from the study at any time. Acceptance to participant in the study was taken through oral consent.

\section{Pilot study:}

A pilot study was conducted on $10 \%$ of the total sample, they were (20) psychiatric patient in the Psychiatric Mental Health Hospital and (20) $4^{\text {th }}$ year basic B.Sc. Nursing students who met the inclusion criteria in order to test the clarity of items, the applicability of the tools and estimate the time needed for data collection. On the bases of the pilot results some modification in the tools was done. Subjects included in the pilot study were excluded from the main studied sample to assure the stability of the results.

\section{Field work:}

The current study was carried out on two phases:

1. The researcher introduced herself to the students and patients then explained the aim of the study to every one of them.

2. Oral consent was taken from every one of patients and students before data collection.

3. An individual interview to collect the necessary data by using the tools for data collection was conducted for every student and patient who met the inclusion criteria and accepted participation in the study.

4. The researcher collected the data from the students and patients in the morning shift 8 a.m.: 2 p.m. in the departments, two days in 
a week; three hours per day, nearly from (10 to 15 patient and student) per week.

5. Each interview lasted nearly half an hour for each patient and student, for three months.

6. Data were collected throughout the period of clinical training of the nursing student from the beginning of February 2019 to the end of April 2019.

\section{Statistical analysis:}

Data entry and statistical analysis were done using the Statistical Package for Social Sciences (SPSS version 20) data were presented using descriptive statistics in form of number and percentages, mean, stander deviation. Qualitative variables were compared using the chi-square test and correlation coefficient was used to measure the direction and strength of the correlation between variables. A statistically significant difference was considered if $\mathrm{p}$-value was $(0.02), \quad(0.013)$ and (0.04). A highly statistically significant difference was considered if p-value was (0.000).

\section{Results:}

Table (1): Reveals that more than half of the studied students $(55.0 \%)$ their age are (22) year old, the mean age of the studied sample is $21.9 \pm 0.67$, near to two thirds $(67.2 \%)$ are male, near to two thirds $(63.9 \%)$ are single, near to one third $(31.1 \%)$ are illiterate, majority $(86.7 \%)$ are not working and more than half $(62.8 \%)$ of them live in rural areas.

Table (4): Represents the distribution of the studied psychiatric patients according to their symptoms of anxiety. Near to one third of studied patients expressed that most of time female, majority (78.9 \%) are single, and near to one third $(30.6 \%)$ of the studied students live in urban areas.

Table (2): Represents the distribution of the studied students according to their communication errors. It illustrate that the majority of the students $80.6 \%$ does not ask if patient has any questions / does not check patient's understanding. More than half of the students uses vague words. Does not support or encourage patient to speak without worry. Does not maintain eye contact. Choses inappropriate time for speech with patient, asks questions to patient in unclear manner. Show fears of the patient's psychological problems. Changes the subject inappropriately, and does not introduce herself/himself to patient and do not explain her/his role at the beginning of interview $(67.8 \%, 65.6 \%, 61.7 \%, 61.1 \%, 60.6 \%, 58.9 \%$, $55.0 \%$, and $52.2 \%$ ) respectively .

Figure(1): Shoes that majority of students $(84.4 \%)$ have communication errors ranged from mild to high communication errors .Nearer to quarter of students (23.9) have high communication errors more than one-third $(37.8 \%)$ of the studied students have moderate communication errors and $(22.8 \%)$ have mild communication errors.

Table (3): Shows that more than onethird $(36.1 \%)$ of the studied patients have 3545 year old, more than two thirds $(67.8 \%)$ are they get upset easily or feel panicky. Feel like he is falling apart and going to pieces, have fainting spells or feel like it, $28.9 \%, 31.1 \%$ and $31.7 \%$ respectively and near to one third of them expressed that a good part of the time that they feel afraid for no reason at all. Bothered by dizzy spells, their hands are 
usually dry and warm and have nightmares, $24.4 \%, 26.7 \%, 27.2 \%$ and $26.1 \%$ respectively.

Figure(2): Shows that majority of the studied patients $(85 \%)$ have anxiety ranged from extreme level to moderate level nearer to one quarter of the studied patients $(22,8 \%)$ suffering from extreme level of anxiety ,more than one-third $(35.6 \%)$ suffering from severe level of anxiety and nearly to one-third (26.7 $\%)$ suffering from moderate level of anxiety.

Table (5): Illustrates that there is statistically significant positive correlation between total mean score of communication errors of the students and total mean score of patients anxiety at $\mathrm{p}$-value $=(0.04)$. This mean when students communication error increase patients anxiety increase.

Table (1): Socio- demographic characteristics of the studied students $(n=180)$.

\begin{tabular}{|c|c|c|}
\hline \multirow[t]{2}{*}{ Socio- demographic characteristics } & \multicolumn{2}{|c|}{ Studied students } \\
\hline & No & $\%$ \\
\hline \multicolumn{3}{|l|}{ Age: } \\
\hline$\geq 21$ year & 45 & 25.0 \\
\hline $21 \geq 22$ year & 99 & 55.0 \\
\hline $22 \geq 23$ year & 36 & 20.0 \\
\hline \multicolumn{3}{|c|}{ Mean \pm SD $=21.9 \pm 0.67$} \\
\hline \multicolumn{3}{|c|}{$x_{1}$} \\
\hline Male & 59 & 32.8 \\
\hline Female & 121 & 67.2 \\
\hline \multicolumn{3}{|l|}{ Marital status: } \\
\hline Single & 142 & 78.9 \\
\hline Married & 38 & 21.1 \\
\hline \multicolumn{3}{|l|}{ Residence: } \\
\hline Rural & 125 & 69.4 \\
\hline Urban & 55 & 30.6 \\
\hline
\end{tabular}




\section{Relationship between Common Errors of Communication among Psychiatric Nursing Students and Anxiety Levels of their Assigned Patients}

Table (2): Frequency distribution of the communication errors among the studied students $(\mathbf{n}=\mathbf{1 8 0})$.

\begin{tabular}{|c|c|c|c|c|c|c|}
\hline \multirow[t]{2}{*}{ Communication errors } & \multicolumn{2}{|c|}{ Yes } & \multicolumn{2}{|c|}{ Some times } & \multicolumn{2}{|c|}{ No } \\
\hline & No & $\%$ & No & $\%$ & No & $\%$ \\
\hline Doesn't great and don't show interest in patient as a person & 66 & 36.7 & 65 & 36.1 & 49 & 27.2 \\
\hline $\begin{array}{l}\text { Doesn't introduce herself/himself to patient and don't explain her/his } \\
\text { role at the beginning of interview }\end{array}$ & 94 & 52.2 & 48 & 26.7 & 38 & 21.1 \\
\hline Doesn't respect patient's privacy & 50 & 27.8 & 90 & 50.0 & 40 & 22.2 \\
\hline Talks using inappropriate literacy level & 83 & 46.1 & 71 & 39.4 & 26 & 14.4 \\
\hline $\begin{array}{l}\text { Uses vague words like "thing" or "it" instead of using the correct } \\
\text { name of a person, place, or things }\end{array}$ & 122 & 67.8 & 36 & 20.0 & 22 & 12.2 \\
\hline Inefficient listening & 88 & 48.9 & 69 & 38.3 & 23 & 12.8 \\
\hline Doesn't maintain eye contact & 111 & 61.7 & 46 & 25.6 & 23 & 12.8 \\
\hline Choses the inappropriate time for the speech with patient & 110 & 61.1 & 56 & 31.1 & 14 & 7.8 \\
\hline The ward over crowded with nursing students & 145 & 80.6 & 34 & 18.9 & 1 & 6 \\
\hline $\begin{array}{l}\text { Uses inappropriate tone, pace, and posture that doesn't show care and } \\
\text { concern to patient }\end{array}$ & 53 & 29.4 & 89 & 49.4 & 38 & 21.1 \\
\hline Makes interruption for patient when talking & 82 & 45.6 & 83 & 46.1 & 15 & 8.3 \\
\hline Talks in judgmental manner & 57 & 31.7 & 72 & 40.0 & 51 & 28.3 \\
\hline Doesn't acceptance and dispraise & 44 & 24.4 & 51 & 28.3 & 85 & 47.2 \\
\hline Doesn’t empathy & 84 & 46.7 & 74 & 41.1 & 22 & 12.2 \\
\hline Doesn't respect patient's need & 54 & 30.0 & 91 & 50.6 & 35 & 19.4 \\
\hline Asks questions to patient in unclear manner & 109 & 60.6 & 62 & 34.4 & 9 & 5.0 \\
\hline Asks questions and gives answers to patient in an aggressive manner & 21 & 11.7 & 66 & 36.7 & 93 & 51.7 \\
\hline Speaks too loudly & 46 & 25.6 & 46 & 25.6 & 88 & 48.9 \\
\hline $\begin{array}{l}\text { Doesn't ask if patient has any questions / doesn't check } \\
\text { understanding }\end{array}$ & 145 & 80.6 & 30 & 16.7 & 5 & 2.8 \\
\hline Doesn't support or encourage patient to speak without worry & 118 & 65.6 & 51 & 28.3 & 11 & 6.1 \\
\hline Uses embarrassing words. & 21 & 11.7 & 69 & 38.3 & 90 & 50.0 \\
\hline Changes the subject inappropriately & 99 & 55.0 & 65 & 36.1 & 16 & 8.9 \\
\hline Reluctance to communicate with the patient & 76 & 42.2 & 73 & 40.6 & 31 & 17.2 \\
\hline Fears of the patient's psychological problems & 106 & 58.9 & 67 & 37.2 & 7 & 3.9 \\
\hline Treats patient in a rude and hasty manner & 50 & 27.8 & 66 & 36.7 & 64 & 35.6 \\
\hline Mean score of communication error & & & \pm 13 & & & \\
\hline
\end{tabular}




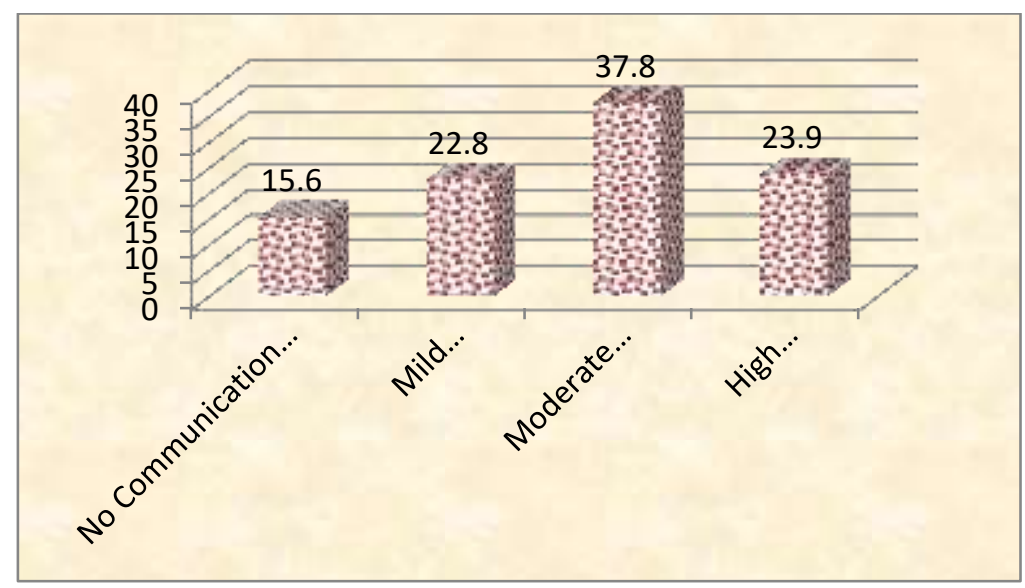

Figure (1): Frequency distribution of the levels of communication errors among the studied students $(\mathbf{n}=\mathbf{1 8 0})$.

Table (3): Frequency distribution of socio-demographic characteristics of the studied patients $(\mathbf{n}=\mathbf{1 8 0})$.

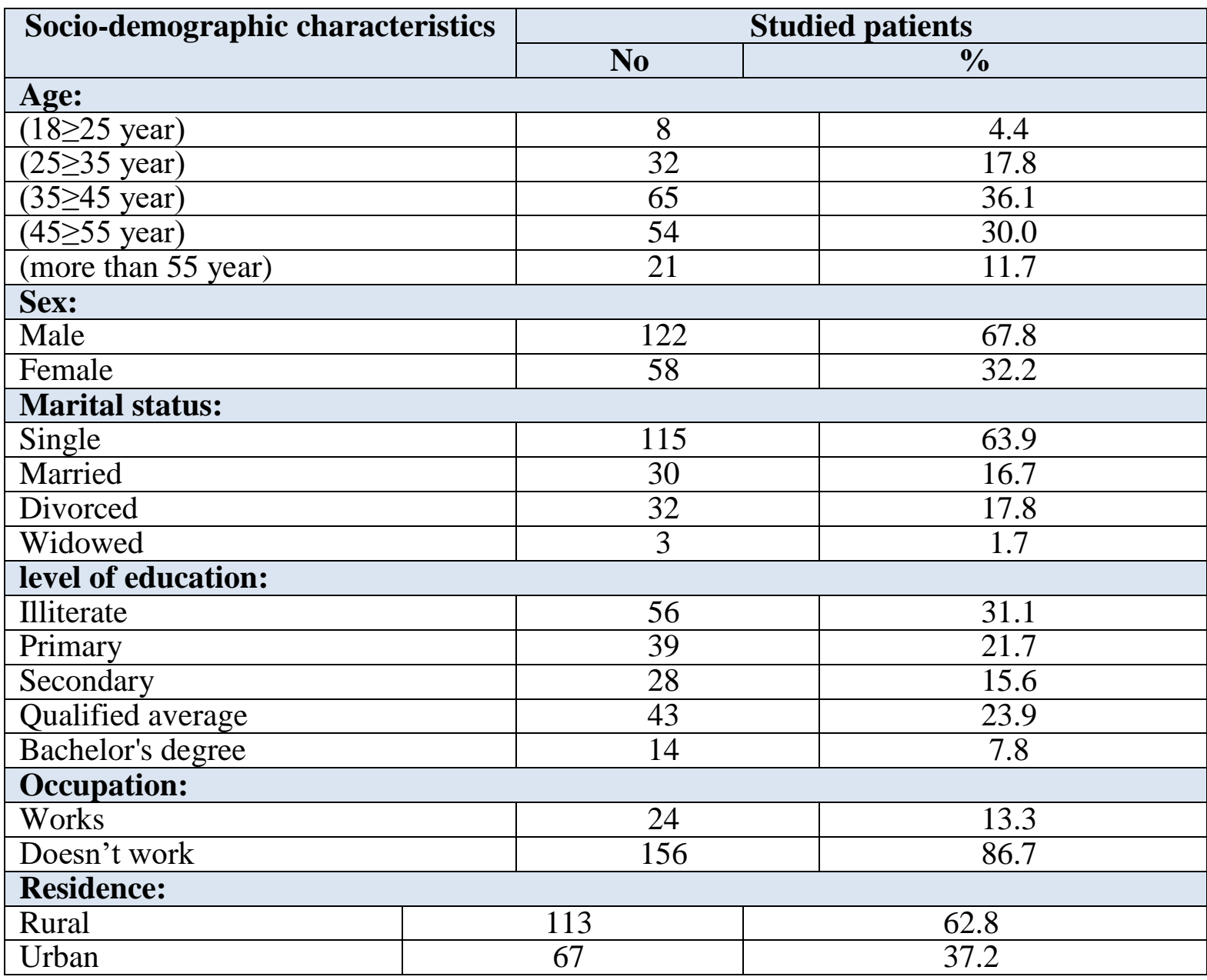


Relationship between Common Errors of Communication among Psychiatric Nursing Students and Anxiety Levels of their Assigned Patients

Table (4): Frequency distribution of the anxiety levels among the studied patients $(n=180)$.

\begin{tabular}{|c|c|c|c|c|c|c|c|c|}
\hline \multirow[t]{2}{*}{ Anxiety symptoms items } & \multicolumn{2}{|c|}{$\begin{array}{l}\text { A little of the } \\
\text { time }\end{array}$} & \multicolumn{2}{|c|}{$\begin{array}{l}\text { Some of the } \\
\text { time }\end{array}$} & \multicolumn{2}{|c|}{$\begin{array}{l}\text { Good part of } \\
\text { the time }\end{array}$} & \multicolumn{2}{|c|}{$\begin{array}{l}\text { Most of the } \\
\text { time }\end{array}$} \\
\hline & No & $\%$ & No & $\%$ & No & $\%$ & No & $\%$ \\
\hline $\begin{array}{l}\text { 1- I feel more nervous and anxious than } \\
\text { usual. }\end{array}$ & 107 & 59.4 & 39 & 21.7 & 27 & 15.0 & 7 & 3.9 \\
\hline 2- I feel afraid for no reason at all. & 68 & 37.8 & 51 & 28.3 & 44 & 24.4 & 17 & 9.4 \\
\hline 3- I get upset easily or feel panicky. & 47 & 26.1 & 46 & 25.6 & 35 & 19.4 & 52 & 28.9 \\
\hline $\begin{array}{l}\text { 4- I feel like I'm falling apart and going } \\
\text { to pieces. }\end{array}$ & 44 & 24.4 & 15 & 8.3 & 65 & 36.1 & 56 & 31.1 \\
\hline $\begin{array}{l}\text { 5- I feel that everything is all right and } \\
\text { nothing bad will happen. }\end{array}$ & 16 & 8.9 & 92 & 51.1 & 60 & 33.3 & 12 & 6.7 \\
\hline 6- My arms and legs shake and tremble. & 106 & 58.9 & 40 & 22.2 & 32 & 17.8 & 2 & 1.1 \\
\hline $\begin{array}{l}\text { 7- I am bothered by headaches neck and } \\
\text { back pain. }\end{array}$ & 116 & 64.4 & 41 & 22.8 & 21 & 11.7 & 2 & 1.1 \\
\hline 8- I feel weak and get tired easily. & 81 & 45.0 & 50 & 27.8 & 33 & 18.3 & 16 & 8.9 \\
\hline 9- I feel calm and can sit still easily. & 25 & 13.9 & 77 & 42.8 & 66 & 36.7 & 12 & 6.7 \\
\hline 10- I can feel my heart beating fast. & 75 & 41.7 & 67 & 37.2 & 30 & 16.7 & 8 & 4.4 \\
\hline 11- I am bothered by dizzy spells. & 69 & 38.3 & 52 & 28.9 & 48 & 26.7 & 11 & 6.1 \\
\hline 12- I have fainting spells or feel like it. & 41 & 22.8 & 16 & 8.9 & 66 & 36.7 & 57 & 31.7 \\
\hline 13- I can breathe in and out easily. & 46 & 25.6 & 104 & 57.8 & 27 & 15.0 & 3 & 1.7 \\
\hline $\begin{array}{l}\text { 14- I get numbness and tingling in my } \\
\text { fingers and toes. }\end{array}$ & 95 & 52.8 & 54 & 30.0 & 25 & 13.9 & 6 & 3.3 \\
\hline $\begin{array}{l}\text { 15- I am bothered by stomach aches or } \\
\text { indigestion. }\end{array}$ & 133 & 73.9 & 30 & 16.7 & 15 & 8.3 & 2 & 1.1 \\
\hline 16- I have to empty my bladder often. & 147 & 81.7 & 26 & 14.4 & 7 & 3.9 & 0 & 0.0 \\
\hline 17- My hands are usually dry and warm. & 54 & 30.0 & 76 & 42.2 & 49 & 27.2 & 1 & .6 \\
\hline 18- My face gets hot and blushes. & 61 & 33.9 & 66 & 36.7 & 31 & 17.2 & 22 & 12.2 \\
\hline $\begin{array}{l}\text { 19- I fall asleep easily and get a good } \\
\text { night's rest. }\end{array}$ & 11 & 6.1 & 82 & 45.6 & 78 & 43.3 & 9 & 5.0 \\
\hline 20- I have nightmares. & 75 & 41.7 & 26 & 14.4 & 47 & 26.1 & 32 & 17.8 \\
\hline Mean score of anxiety & & & & & \pm 12. & & & \\
\hline
\end{tabular}




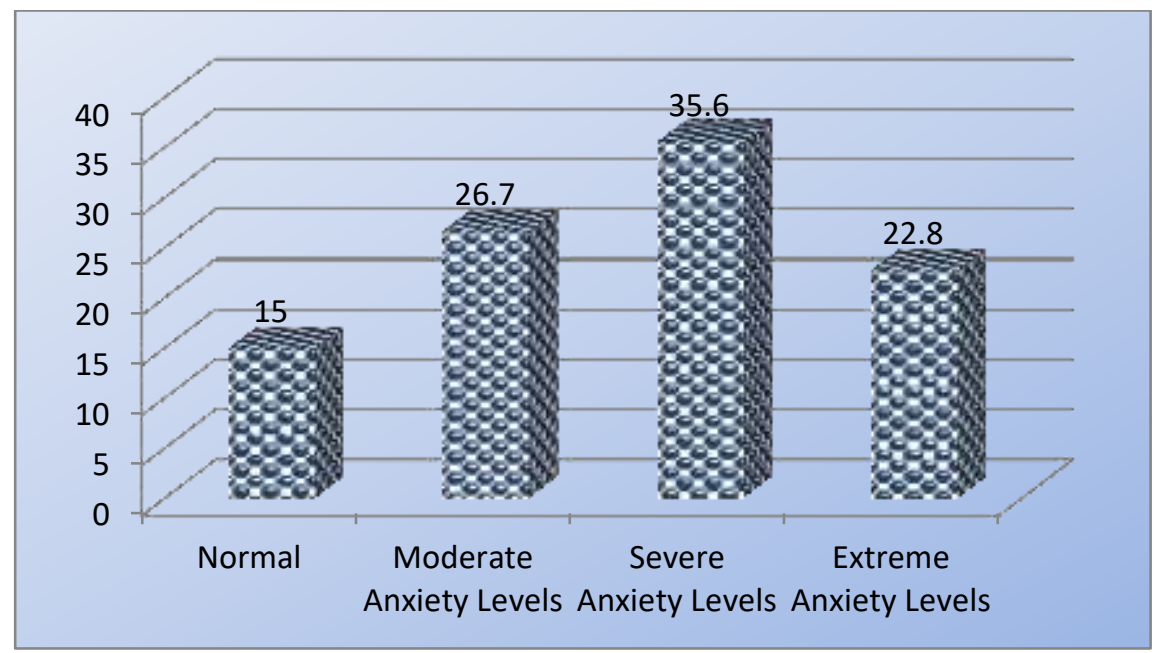

Figure (2): Frequency distribution of anxiety level among the studied patients $(n=180)$.

Table (5): Correlation between total communication errors and total anxiety levels.

\begin{tabular}{|c|c|c|}
\hline Items & \multicolumn{2}{|c|}{ Total anxiety mean score } \\
\hline Total communication & $\mathrm{r}$ & $\mathrm{p}$-value \\
\cline { 2 - 3 } errors mean score & 0.73 & $0.04 *$ \\
\hline
\end{tabular}

*Statistical significance.

\section{Discussion}

Communication is the key factor in providing and managing the care of patients with mental illness. The nurse-patient relationship is the core of mental health nursing and the behaviors of both nursing student and patient interacting together play a significant role in the quality of patient care and its outcomes. Although communication is the foundation of the nurse-patient relationship, psychiatric nurses have been criticized for their lack of interaction and therapeutic engagement with patients (Arnold \& Boggs, 2017).

Therapeutic communication is a combination of verbal and nonverbal communication techniques that helps improve a patient's physical and mental wellbeing, and help the nursing student to gain the trust of patients. (Hammer et al., 2014). Thus, nontherapeutic communication involves various words, phrases, actions, and tones that make a patient feel uncomfortable, increase their stress, anxiety, and worsen their overall mental, and perhaps even physical, wellbeing. Non-therapeutic communication can lead to unintentional miscommunication between the nursing student and the patient (Chard \& Makary, 2015).

This study aimed to assess the relationship between common errors of communication among psychiatric nursing students and anxiety levels of their assigned patients during their clinical practice at 
Psychiatric and Mental Health Hospital in Benha City.

Regarding to socio-demographic characteristics of studied students, the result of the present study revealed that, more than half of the studied students aged 22 year old, the mean age of the studied sample was $21.9 \pm 0.67$. From the researcher point of view, this might be due to the study was conducted on nursing students at fourth year only. This results were in the same line with Jamshidi et al., (2016) found in his study that the participants consisted of seventeen nursing students aged 20-23 years. Also this result similar to the study done by Demir \& Ercan, (2018) reported that the average age was $21.6 \pm 0.83$, ranging from 21.0 year to 23.0 year.

Concerning to student's gender, the current study result revealed that near to twothirds were female. This result could be due to Egyptian society value, girls enrollment in nursing colleges was more than boys. This results came in agreement with a study done by Szpak \& Kameg, (2017) found that the majority of nursing students were females and only one-quarter were males.

Concerning to student's marital status, the current study result revealed that majority were single. This may be due to Students were still in the education stage, and the college of nursing is a practical college, so it was difficult for students to combined studies and marriage. This results came in agreement with a study similar done by Demir \& Ercan, (2018) reported that twelve students were single, and three students were married.

Regarding to residence of studied nursing students, the majority of studied students were from rural area. This may be due to Benha city near from rural area. This finding was similar to the study done by Jamshidi et al., (2016) reported that the more than twothird of the studied nursing students were lived in rural areas.

Regarding to the distribution of the studied students according to their communication errors. The current study illustrate that the majority of the studied students had communication errors ranged from mild to high communication errors .Nearer to quarter of students had high communication errors more than one-third of the studied students had moderate communication errors From the researcher point of view this might be due to lack of nursing students awareness of communication skills, fear from psychiatric clinical area, and lack of students training about technique of communicating skill with patients and how to interact with them. This result came in agreement with a study done by Jamshidi et al., (2016) reported that many students mentioned the lack of communication skills as the reason for deficiency in communicating with the clinical learning environment. Ensuring that students were utilizing appropriate communication skills was difficult due to higher psychiatric patient acuity, shorter hospital stays, and increased faculty to student ratios in the clinical setting. Also, this result was consistent with Erchul et al., (2014) found that communication with the patient who was admitted with mental health challenge was complex. When the patient was in a crisis, most patients undergo physical or psychological changes. Pain, anxiety or fear could cause patients to deal with their problems 


\section{Walaa Farahat Elsobky, Maaly Ibrahim El-Malky and Faten Mohamed Ahmed}

differently than they were healthy and in a familiar environment.

According to Rose, (2019) who result was congruent with this result who reported that some psychiatric patients on an acute inpatient or long-term psychiatric unit who were diagnosed with major depressive disorder, psychotic disorder, or a personality disorder may experience a severe psychosis, may be severely depressed, may express suicidal or thoughts of self-injury and display aggressive behaviors. These patients need to be maintained in a safe environment. Many psychiatric nurses feel that their ability to communicate, assess, and treat such patients appropriately was inadequate. This creates tension in providing care and hinders the development of the nursepatient relationship.

Regarding to socio-demographic characteristics of studied patients, the result of the present study showed that more than onethird of the total studied patients their age ranged between 35-45 years. This may be due to environmental factor which trigger genetic factor as many pressures of practical, financial, and family life, etc. this result agreed with Becker, (2014) stated that near to half of the studied sample ranged from 35 to less than 45 years.

Concerning to patient's gender, the current study result revealed that more than two-thirds were males. This may due to male patients were usually carrying the burden of financial responsibility for their families or may be due to female have ability to tolerate stress than male. These results were similar to a study done by San et al., (2013), who found that more than half of the studied group was males.
Concerning to patient's marital status, the current study result revealed that near to two-thirds were single. This could be due to the psychiatric patient may experience difficulties in the social relationship due to social stigmatization that led to reduce opportunities for socialization and marriage. This result was consistent with Koujalgi \& Patil, (2013) found that the majority of the studied patients were single. While contradicted with Ebrahimi et al., (2014) found that the majority of studied patients were married.

As regards to the educational level, the result of the present study revealed that near to one-third of the patients sample was illiterate. This could be due to the cognitive and symptomatic impairments that interfered with their ability for learning. This result was consistent with Hassinine, (2015) whose study revealed that the same result, one-third of the study sample was illiterate. This may be justified by illiteracy which made patients not have the interest to know, learn and retain information.

Regarding occupation, the present study result showed that the majority of the total patients sample were unemployed. This may be due to those patients with psychiatric disease had long-standing deficits in their performance of even the most basic social roles and skills required for work. This finding was consistent with Alma et al., (2012) who indicated that repeated of psychiatric disease episodes led to the damage of the working functionality.

As regards to the residence, the present study revealed that more than half of the total patients sample was living in rural areas. This result was congruent with Mohamed \& Abdel 
Hamed, (2012) declared in their results that nearly three-quarters of the studied group were living in rural areas. While contradicted by Corredor-Rozo et al., (2013) showed that the majority of the studied patients resided in urban areas.

The present study revealed that the majority of the studied patients had anxiety ranged from extreme level to moderate level nearer to one quarter of the studied patients were suffering from extreme level of anxiety, more than one-third suffering from severe level of anxiety and nearly to one-third suffering from moderate level of anxiety. This might be due to the majority of studied nursing students had communication errors ranged from mild to high communication errors that elevated the level of anxiety of the studied psychiatric patients. This result went parallel with Loghmani, et al., (2014) stated that anxiety is one of the major mental problems in a family. The major concern of the patients to treatment costs, dismiss and outcome of the disease were the major cause of anxiety.

Regarding relationship between communication errors of psychiatric nursing students and anxiety levels of their assigned patients. The current study reveals that there was statistically significant positive correlation between total mean score of communication errors of the students and total mean score of patients anxiety. This is meant that when students communication error increased, patients anxiety level increased. This result was consistent with Houwen et al., (2019) found that the level of anxiety of psychiatric patients was associated with communication error of nursing students, higher level of anxiety was connected to more severe of communication errors. On the other hand, this result had disagreed with Dawood et al., (2018) found in his study that carried out on the psychiatric patients and nursing staff the result of study revealed that no correlation between the presence of anxiety symptoms and the nursing communication errors.

\section{Conclusion}

Most of the psychiatric patients have anxiety symptoms ranged from mild, moderate and severe; the comorbid anxiety symptoms are highly prevalent among psychiatric patients due to communication errors of nursing students. there was a positive correlation between level of anxiety of psychiatric patients and communication errors of nursing students, when communication errors increases levels of anxiety increases.

\section{Recommendations}

- Educational programs of communication skills should be conducted for all nursing students before clinical training to improve their communication skills and minimize their communication errors when communicating with patients .

- Stress management and assertiveness training program should be given to psychiatric patients to relieve their psychological problems, decrease their level of anxiety and enhance their coping patterns.

- Future research with a larger sample is recommended to attain more generalizable results.

\section{References}

Alma B., Bajro T., Lilijana O., and Abdulah K. (2012). Patients outcomes of 


\section{Walaa Farahat Elsobky, Maaly Ibrahim El-Malky and Faten Mohamed Ahmed}

schizophrenia in relation to socio demographic characteristics and psychopathology. Medical Journal, 2012; 18(3): p176.

Arnold E., and Boggs k. (2017).Interpersonal Relationship , Professional Communication Skills for Nurses , 5th ed , Com ., Louis , Saunders, ; 311- 313.

Bayoumi M.M.M., Elbasuny M.M.M., Mofereh A.M., Assiri M.A.M., and Alfesal A.H. (2012). Evaluating NursingStudents' Anxiety and Depression during Initial Clinical Experience. International J. of Psychology and Behavioral Sci., 2012; 2(6): 277-281.

Becker T. (2014). Re-hospitalization risk of former voluntary and involuntary patients with schizophrenia. Social psychiatry, (2014); Vol (5): Pp20.

Chard R., and Makary M.A. (2015). Transfer-of-Care Communication: Nursing Best Practices. AORN Journal, 2015; 102(4): 329-342.

Corredor-Rozo Z. Y., Sanchez-Espinosa M. P., Rondon-Lagos M., Paes Rojas P. L., Duque R., and Castro M. F. (2013). Descriptive study of 20 patients with schizophrenia in Boyaca, Colombia. Investigation Original, 2013; 26(3): ISSN 0121-0793.

Cvetic E. (2018). Communication in the perioperative setting. Association of perioperative registered nurses journal, Sep 2018; 94(3) p261-70.

Dawood E., Mitsu R., Alharbi M., Almurairi A., Kanori H., Alsaiari M., and Alqarni K. (2018). Relationship between Nurses' Communication and Levels of Anxiety and Depression among Patient's
Family in the Emergency Department. Ann Psychiatry Mental Health, 2018; 6(1): 1125.

Demir S., and Ercan F. (2018). The first clinical practice experiences of psychiatric nursing students: A phenomenological study. Nurse Education Today, 2018;(61), 146-152.

Ebrahimi H., Navidian A., and Keykha R. (2014). Effect of supportive nursing care on self-esteem of patients receiving electroconvulsive therapy: A Randomize Controlled Clinical Trial. Journal of Caring Sciences, 2014; 3(2): 149-156.

Erchul W.P., Martens K., and Caplan S. (2014). Preventive Model. School Consultation; Conceptual and Empirical Bases of Practice.3rd Ed. Springersny. Chapter 5. $33 ; 90$.

Fay-Hillier T.M., Regan R.V., and Gallagher G.M. (2012). Communication and patient safety in simulation for mental health nursing education. Issues Ment Health Nurs, 2012; 33(11): 718-726.

Hall K. (2017). Simulation-based learning in Australian undergraduate mental health nursing curricula: a literature review. Clin Simul Nurs., 2017;13(8): 380-9.

Hammer M., Fox S., and Hampton M.D. (2014). Use of therapeutic communication simulation model in pre-licensure psychiatric mental health nursing: Enhancing strengths and transforming challenges. Nursing and Health, 2015; 2(1): 1-8.

Hart A. V. (2018). Personal and professional relationships and communication. In patientprovider communications, 2018; Pp 99-102. Sudbury, Massachusetts: Jones and Bartlett. 
Hassinine H. (2015). Factors affecting rehospitalization of schizophrenic patients at Benha Mental Health Hospital, Master thesis. Faculty of Nursing, Benha University, Pp. 41-78.

Houwen M.D.J., Bas J.E., and Moorthaemer M.D. (2019). The association between patients' expectations and experiences of task-, affect- and therapyoriented communication and their anxiety in medically unexplained symptoms consultations, 2019; 22(3): 338-347.

Jamshidi N., Molazem Z., Farkhondeh S., Torabizadeh C., Kalyani M.N., (2016). The Challenges of Nursing Students in the Clinical Learning Environment: A Qualitative Study", The Scientific World Journal, 2016; vol., Article ID 1846178, P7.

Koujalgi S. R., and Patil S. R. (2013). Comparison of demographic profile of patients with schizophrenia and anxiety. Karnatak Lingayat Education Society University, Belgaum, Karnataka. J Sci. Soc., 2013; 40(1): 20-24.

Liaw S.Y., Zhou W.T., Lau T.C., Siau C., and Chan S.W.C. (2014). An interprofessional communication training using simulation to enhance safe care for a deteriorating patient. Nurse Educ Today, 2014; 34(2): 259-264.

\section{Loghmani L., Borhani F., and Abbaszadeh} A. (2014). Factors affecting the nurse-patients' family communication in intensive care unit of Kerman: a qualitative study. Journal of caring sciences, 3(1), 67-82. https://doi.org/10.5681/jcs.2014.008.
Marzieh A.O., Mehrinejad S.A., Hashemianb K., and Paivastegarb $M$. (2020). Integrative therapy (short-term psychodynamic psychotherapy \& cognitivebehavioral therapy) and cognitive-behavioral therapy in the treatment of generalized anxiety disorder: A randomized controlled trial. Complementary Therapies in Clinical Practice, ELSEVIER, Volume 39, January 2020, 101122.

Mohamed N. A. and Abd El-Hameed N. A. (2012). The effect of cognitive behavior therapy program on insight and nonadherence to medication among psychotic patients in Psychiatric Hospital at Assiut Governorate. (Published Doctoral Dissertation). Life Science Journal, 2012; 9(2): 435-441.

Pesut D., Descotes J., Talaga P., Jeffrey M. W., Debomoy K. L., and Looney R. (2019). Core communication skills in mental health nursing. Clinical Practice \& Epidemiology in Mental Health, 2019; Vol 15; 1745.

Poyato A.R.M., Curto P.M.,Hito P.D., Perez R.S., Dominguez R.A., Salvador R.C., Moral J.m.L., Canut T.L., and Merino J.F.R. (2016). The Therapeutic Relationship in Inpatient Psychiatric Care: A Narrative Review of the Perspective of Nurses and Patients. Arch.Psychiatr. Nurs. 2016; 30(6): 782-787.

Raya A. (2018). Nursing of man as a unique person nosileftiki, 2014; 45(1): 19-24.

Rose L. M. (2019). Communication skills of novice psychiatric nurses with aggressive psychiatric patients published doctor theses 
faculty of health sciences Walden university 2019.

San L., Gomez A., Martin Z. P., and Pena M. (2013). Socio-demographic, clinical and treatment characteristics of relapsing psychiatric patients. Nord J Psychiatry, 2013; 67(1): Pp. 22-9.

Szpak J. L., and Kameg K. M. (2017). Simulation Decreases Nursing Student Anxiety Prior to Communication with Mentally Ill Patients. Clinical Simulation in Nursing, 2017; 9(1): 13-19 .

Wedgeworth M. (2016). Anxiety and Education: An Examination of anxiety Across a Nursing Program. Journal of Nursing Education and Practice, 2016; 6(10): 23-32.

Wiltgen A., Arbona C., Frankel L., and Frueh C.B. (2015). Interpersonal trauma, attachment insecurity and anxiety in an inpatient psychiatric population. Journal of Anxiety Disorders, 2015; 35: 82-87. 
العلاقة بين الأخطاء الثائعة للتواصل لاى طلاب التمريض النفسي ومستويات القلق لدى المرضى المعينيين لايهم

ولاء فرحات عبد العزيز السبكى _ معالى ابراهيم المالكى _ فاتن محمد احمد

يكون معدل التوتر و القلق و الاكتئاب مرتفعًا بشكل عام لدى المرضى النفسيين و أخطاء التو اصل تعكس

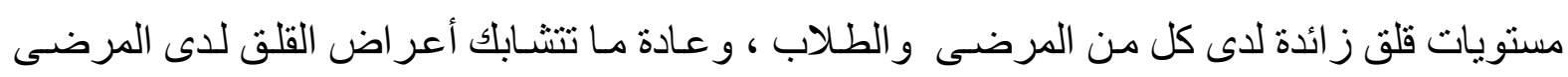
النفسيين مع أخطاء التو اصل لدى طلاب التمريض. لذللك هدفت هذه الدر اسة الي تقييم العلاقة بين أخطاء

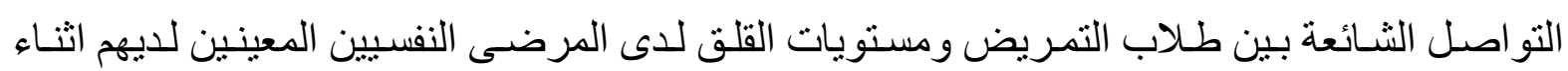
تجاربهم العملية ، وقد أجريت الدر اسـة بمستثفى الصحة النفسية و الادمـان بمدينة بنها التابعة للأمانـة

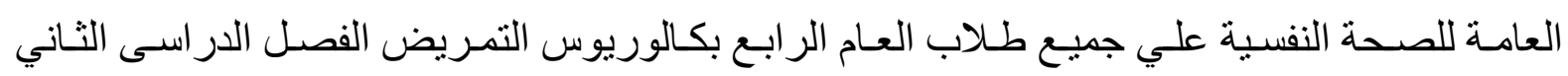

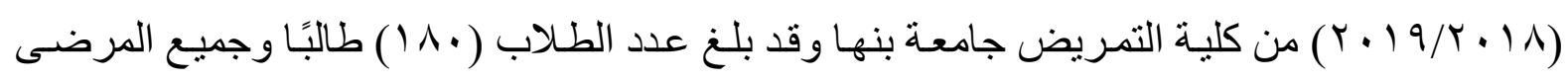

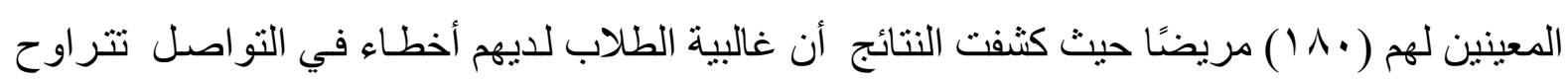

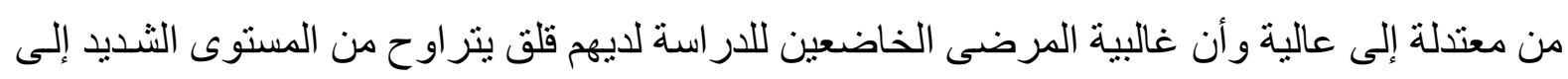

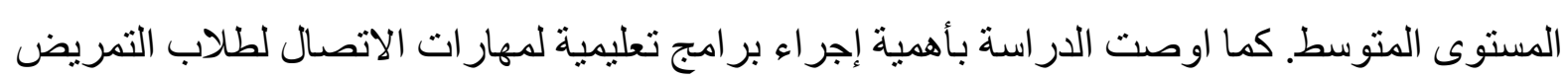

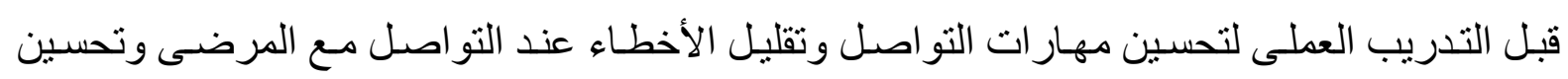
نوعية حياتهر. 